comed aty
International Journal of Environmental Analytical

Chemistry

\title{
Modified carbon paste electrode for the electrochemical sensing of 3,5,6-trichloro-2- pyridinol
}

André Luiz dos Santos, Elisete A. Batista, Luís Moreira Gonçalves \& Maria del Pilar T. Sotomayor

To cite this article: André Luiz dos Santos, Elisete A. Batista, Luís Moreira Gonçalves \& Maria del Pilar T. Sotomayor (2017) Modified carbon paste electrode for the electrochemical sensing of 3,5,6trichloro-2-pyridinol, International Journal of Environmental Analytical Chemistry, 97:2, 159-167, DOI: $10.1080 / 03067319.2017 .1291809$

To link to this article: https://doi.org/10.1080/03067319.2017.1291809

曲 Published online: 20 Feb 2017.

Submit your article to this journal $₫$

Џ Article views: 95

View Crossmark data ¿

Citing articles: 2 View citing articles 주 


\title{
Modified carbon paste electrode for the electrochemical sensing of 3,5,6-trichloro-2-pyridinol
}

\author{
André Luiz dos Santosa, Elisete A. Batistaa, Luís Moreira Gonçalves $\mathbb{1}^{\mathrm{b}}$ \\ and Maria del Pilar T. Sotomayor ${ }^{a}$
}

aDepartamento de Química Analítica, Instituto de Química, UNESP-Univ Estadual Paulista, Araraquara,

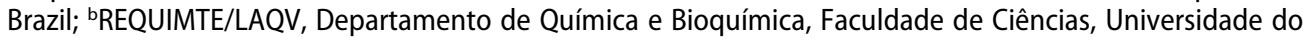
Porto (FCUP), Porto, Portugal

\begin{abstract}
An electrochemical sensor for the determination of 3,5,6-trichloro-2-pyridinol (TCP), the main metabolite of the pesticide chlorpyrifos, was herein developed. TCP has greater solubility than the source pesticide, and its occurrence in ground and surface water is more frequent and more dangerous. The sensor was fabricated using carbon paste modified with the inorganic complex chloro-5,10,15,20-tetrakis-(pentafluorophenyl)-21 $\mathrm{H}, 23 \mathrm{H}$-porphyrin iron(III) (FeTPPCl); this metallic complex has a chemical core structure similar to the heme cofactor of the cytochrome P450 (CYPs). Measurements were performed with square-wave voltammetry. Using the optimised voltammetric parameters and without any sample preparation, the sensor showed a limit of detection of $2.8 \mathrm{mg} \mathrm{L}^{-1}\left(14 \mu \mathrm{mol} \mathrm{L}^{-1}\right)$, recoveries ca. $102 \%$, suitable selectivity and long durability (over 1 month).
\end{abstract}

\section{ARTICLE HISTORY}

Received 12 September 2016 Accepted 31 January 2017

\section{KEYWORDS}

Biomimetic sensor; electroanalysis; insecticide; Iron porphyrin complex; modified carbon paste electrode

\section{Introduction}

Chlorpyrifos is a pesticide used to control mosquitos and flies. Though its residential use has been progressively eliminated, it is still one of the most sold pesticides in the world, including in countries with more developed economies [1-3]. Chlorpyrifos has been reported as the second most commonly detected pesticide in food and water [2]. It has limited solubility and a high soil sorption coefficient. It acts by direct contact and by ingestion. Organophosphorus insecticides connect to the stearic centre of acetylcholinesterase (AChE) inhibiting its function to hydrolyse the neurotransmitter acetylcholine (ACh). Thus, it interferes with the transmission of nervous impulses in insects leading to their death [4,5]. This AChE binding can also occur in humans causing nausea, convulsions, and, with large exposition, respiratory problems and even death. It may be particularly dangerous to pregnant women due to its possible teratogenicity [1].

One of the main hydrolysis products of chlorpyrifos is 3,5,6-trichloro-2-pyridinol (TCP). TCP not only might serve as biomarker for chlorpyrifos contamination, since it 
is more stable, but it should also be monitored since it is considered to be a more hazardous pollutant than the parent compound [2,6], which is in part explained by the fact that TCP is 20 times more soluble than chlorpyrifos [6].

In a literature search, one can find a large variety of immunoassays for the determination of TCP [7-12] and some chromatographic procedures [13] that can be associated with sample preparation techniques like solid-phase extraction [14] or liquid-liquid [6,15]. However, eletroanalytical alternatives are rather scarce $[16,17]$. Liu et al. developed a sequential injection analysis system with a thin-layer electrochemical flow cell containing a magnet that fixed TCP antibody-coated magnetic beads; these beads competitively reacted with TCP and horseradish peroxidase (HRP)labelled TCP, being the HRP activity monitored by square-wave voltammetry achieving a limit of detection (LOD) of $6 \mathrm{ng} \mathrm{L}^{-1}$ [16]. Wang et al. presented a portable immunochromatographic electrochemical biosensor working by also measuring HRP activity by square-wave voltammetry, albeit in a different sensor configuration, the obtained LOD was $0.1 \mu \mathrm{g} \mathrm{L}^{-1}$ [17].

In this work, a sensor was developed for the swift detection of TCP by square-wave voltammetry; this sensor made use of a carbon paste modified with a metallic complex mimicking the catalytic action of CYP 450.

\section{Experimental}

\subsection{Reagents}

All chemicals were of analytical grade and were used as received without further purification. Pesticides (TCP and all other used in the selectivity tests), the metallic complexes, the mineral oil (Nujol) and the graphite powder were all purchased from Sigma-Aldrich, St. Louis, USA. Ultrapure water (resistivity not lower than 18.2 $\mathrm{M} \Omega \mathrm{cm}$ at $298 \mathrm{~K}$ ) from a Direct-Q 3 UV water purification system (Millipore, Billerica, USA) was used in all experiments.

\subsection{Sensor preparation}

Several steps were carried out to prepare the carbon-paste-modified electrodes: (1) $25 \mathrm{mg}$ of the modifying agent, that is, the metallic complex, was mixed with $75 \mathrm{mg}$ of graphite powder; (2) addition of $1 \mathrm{~mL}$ of buffer phosphate, $0.1 \mathrm{~mol} \mathrm{~L}{ }^{-1}, \mathrm{pH} 7.0$; (3) the mixture was slowly dried at room environment for about $24 \mathrm{~h}$; (4) over the dried material, $60 \mu \mathrm{L}$ of the glutting agent, that is, the mineral oil, was added, and after homogenisation, the modified carbon paste was considered ready and kept dry.

The paste was placed in the working electrode surface previously cleaned with isopropyl alcohol. The working electrode consisted in a glass cylinder with a platinum wire in the middle; the paste was deposited on a cavity of $1 \mathrm{~mm}$ depth and $3 \mathrm{~mm}$ diameter holding a small platinum disc in the base [18]. 


\subsection{Apparatus}

Electrochemical measurements were performed in a $\mu$ Autolab controlled with software GPES v.4.9. A three-electrode system was used; it was composed of a platinum wire as the counter-electrode, a $\mathrm{Ag} \mid \mathrm{AgCl}$ (in saturated $\mathrm{KCl}$ ) electrode as the reference electrode and the previously mentioned modified carbon electrode as the working electrode.

All measurements were performed at room temperature and without degasification with nitrogen. Between measurements the working electrode was polished and kept in a dry place.

\section{Results and discussion}

Biomimetic sensors have been used to obtain a more stable response than conventional biosensors that use a biological element. These devices aim to solve the limitations of enzymatic sensors like cost and stability while maintaining selectivity. Cytochromes P450 (CYPs) are proteins present in the human liver involved in metabolising many different substances, including pharmaceuticals and, notably for this work, pesticides. CYPs are hemoproteins, that is, they contain an heme group as a co-factor. It was precisely the catalytic activity of this group that authors tried to mimic in this work (Figure 1). Several different metallic complexes were tested, namely: 5,10,15,20-tetrakis(pentafluorophenyl)-21 H,23 Hporphyrin iron(III) chloride (FeTPPCI), copper(II) phthalocyanine, cobalt(II) phthalocyanine, iron (II) phthalocyanine bis(pyridine) cobalt(II) 1,2,3,4,8,9,10,11,15,16,17,18,22,23,24,25-hexadecafluoro-29 H,31 $\mathrm{H}$-phthalocyanine, 5,10,15,20-Tetrakis(4-methoxyphenyl)-21 $\mathrm{H}, 23 \mathrm{H}$-porphine cobalt(II) and Iron(III) phthalocyanine chloride. Of all these complexes, FeTPPCI was chosen to carry out the rest of the experiments; this choice was based in the larger signal gain on the TCP

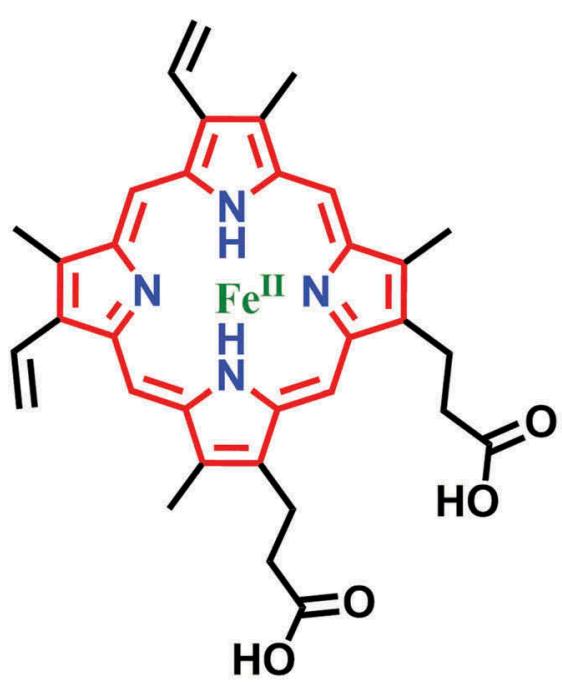

Heme B

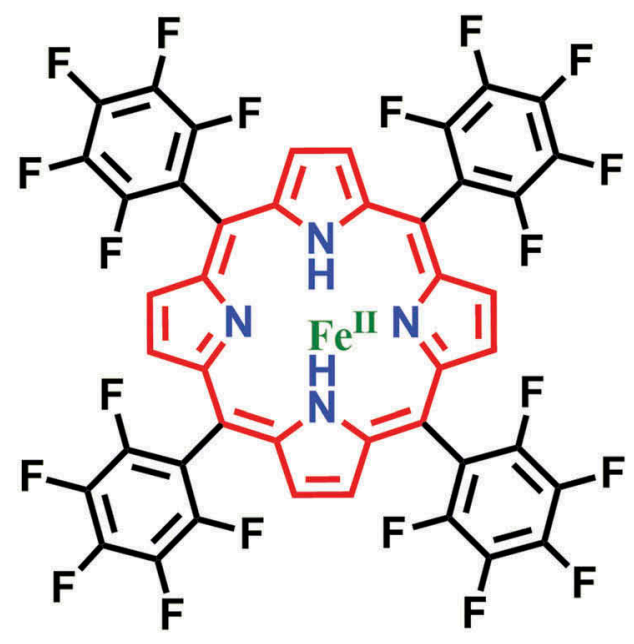

FeTPPCI

Figure 1. Heme B and FeTPPCl structures. 
analysis when compared to the non-modified carbon paste electrodes. Although this signal gain was quite modest (ca. 30\%), the greatest advantage seemed to be a greater linearity between signal and concentration. The quantity of the metallic complex within the paste was also subsequently optimised (the following percentages were tested with a TCP calibration curve with concentration from 0.11 to $0.61 \mathrm{~g} \mathrm{~L}^{-1}: 0 \%, 5 \%, 10 \%, 15 \%, 20 \%, 25 \%$ and $30 \%$ ), there was a large increase in signal starting at $15 \%$ that remained rather constant up to $30 \%$ (data not shown), a percentage of $25 \%$ was chosen to perform the following experiments.

To better understand the process, scan-rate experiments were performed, results are shown in Figure 2. It is known that for a fully diffusional process, in cyclic voltammetry, peak current is proportional to the square root of the scan rate and for a fully adoptional process, peak current is proportional to the scan rate $[18,19]$. This means that by plotting logarithm of peak current versus logarithm of scan rate, for a diffusional process the slope is 0.5 and for an adsorptive process the slope is 1.0, and one could expect a value between for a mixed process [20,21]. As can be observed in the inlays of Figure 2 , in this case we have a mostly diffusional process, thus, due to the irregular surface some quasi adsorptive processes might be found to be occurring in simultaneous. The peak potential corresponding to TCP was around $0.0 \mathrm{~V}$ versus $\mathrm{Ag} \mid \mathrm{AgCl}$, and the peak present at $-0.5 \mathrm{~V}$ versus $\mathrm{Ag} \mid \mathrm{AgCl}$ corresponds to the oxidation of the metallic complex as can be found in literature [22].

Square-wave voltammetry was applied to increase sensitivity $[23,24]$. Optimised square-wave voltammetric parameters were the following: square-wave frequency of $50 \mathrm{~Hz}$, wave amplitude of $150 \mathrm{mV}$ and potential step of $1.5 \mathrm{mV}$ (Figure 3). A calibration curve $(n=28)$ was constructed to evaluate the sensor's analytical parameters: coefficient of determination $\left(r^{2}\right)$ of $0.994, i_{p}(A)=(4.0 \pm 0.2) \times[T C P]$ $\left(\mathrm{g} \mathrm{L}^{-1}\right)-(21 \pm 5)$, linear range up to $0.17 \mathrm{~g} \mathrm{~L}^{-1}$, LOD and limit of quantification (LOQ) of 2.8 and $9.3 \mathrm{mg} \mathrm{L}^{-1}$ (i.e. 14 and $47 \mu \mathrm{mol} \mathrm{L}^{-1}$ ), respectively. LOD and LOQ were calculated as 3 and 10 times the standard deviation of the intercept/slope, respectively. When compared to the LODs of other electroanalytical methodologies $[16,17]$, the obtained LOD is indeed higher, however in those cases immunoelectrochemical methodologies with indirect determination were employed. The intraday repeatability was around $7.5 \%$ and inter-day repeatability was around $4.8 \%$ (seven calibrations curves, with seven points each, performed in five consecutive days).

To estimate the electrode's durability, the same carbon paste was monitored for around 40 days. This monitoring consisted on making a repeating a calibration curve with seven different concentrations and then compare the obtained slopes, that is, comparing sensitivities. Measurements were performed in the 1st, 2nd, 3rd, 4th, 7th, 14th, 22nd, 31st and 39th day. Only in the 39th a sensitivity below $70 \%$ was obtained, in fact in the 31st it was around 94\%, this shows that the paste's life time is ca. 1 month. Since this sensor does not make use of any biological element it is not surprisingly that it possesses such durability [25].

To check the sensor selectivity, other five common pesticides were tested: metribuzin, chlorpyrifos, 2,4-dichlorophenoxyacetic acid, carbofuran and profenofos. All these compounds have limited solubility in aqueous solutions, thus we analysed saturated solutions in phosphate buffer, not knowing the precise 


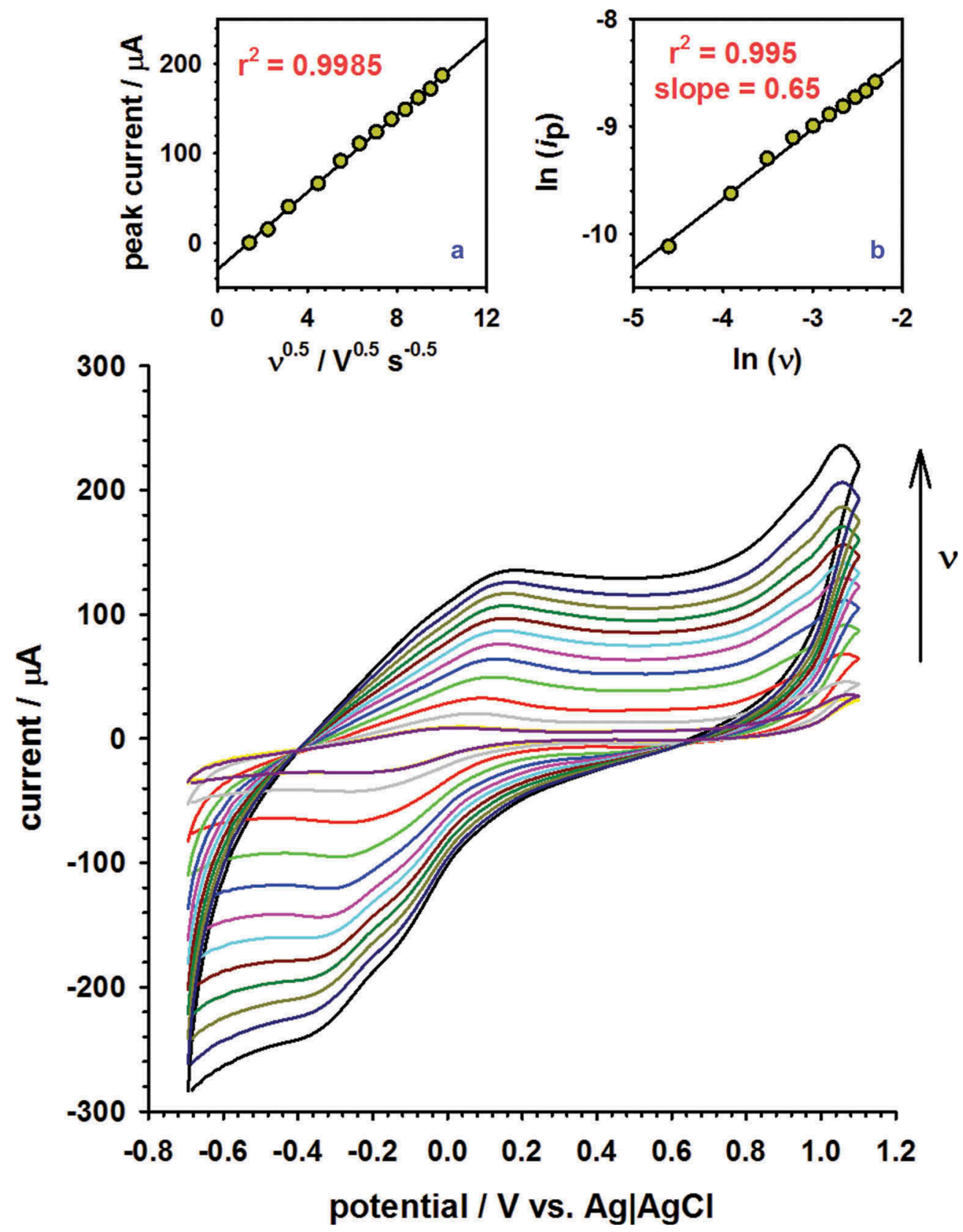

Figure 2. Cyclic voltammetry measurements obtained in the analysis of TCP, $2.08 \times 10^{-2} \mathrm{~g} \mathrm{~L}^{-1}$, in phosphate buffer $0.02 \mathrm{~mol} \mathrm{~L}^{-1}, \mathrm{pH} 6.0$, at different scan rates (from 2 to $100 \mathrm{mV} \mathrm{s}^{-1}$ ). Inlay A: Linear variation of peak current as a function of the square root of the scan rate. Inlay B: Linear variation of the logarithm of peak current as a function of the logarithm of the scan rate. 


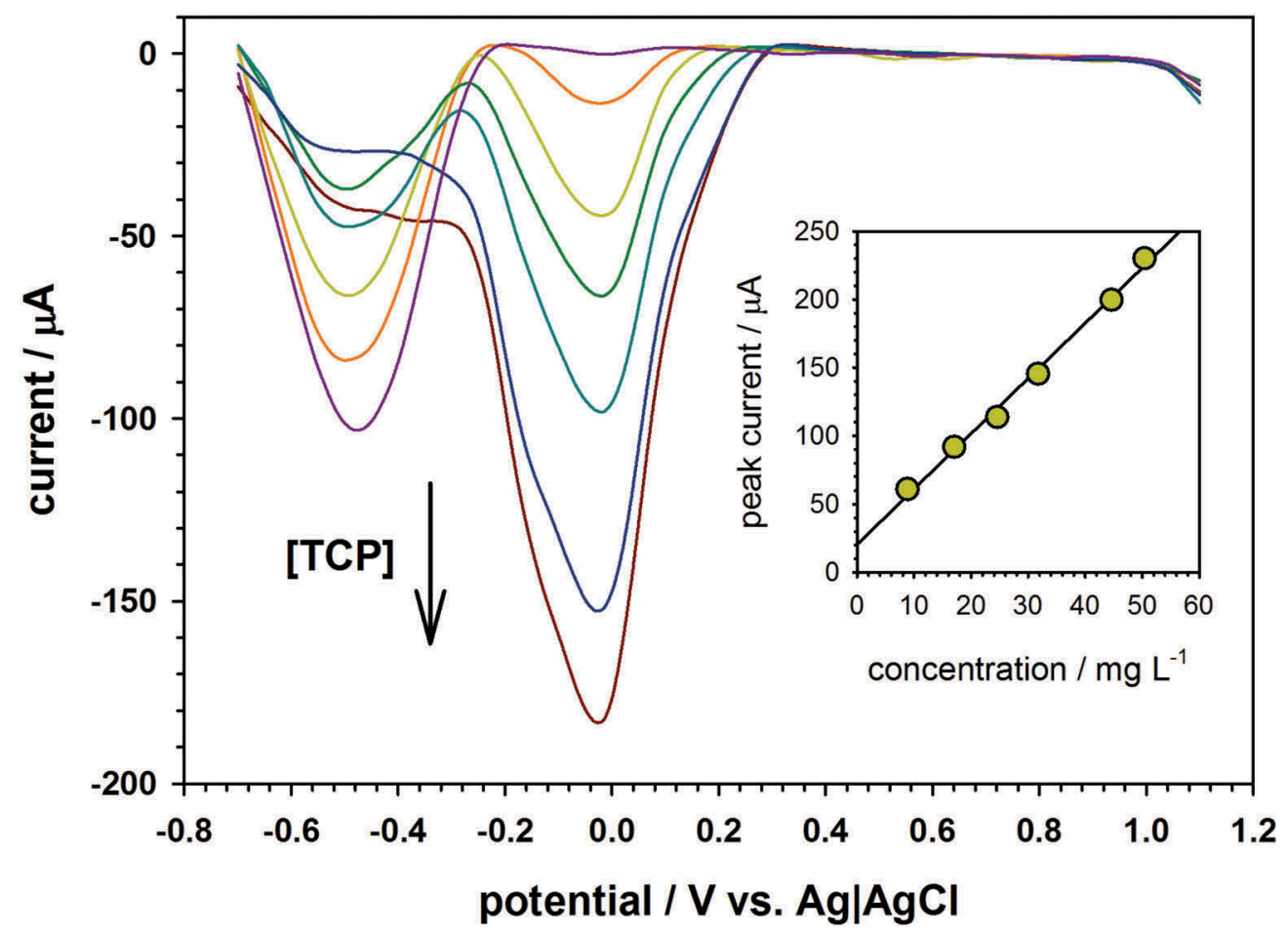

Figure 3. Square-wave voltammograms of TCP, concentrations from $8.73 \times 10^{-3}$ to $4.96 \times 10^{-2}$ $\mathrm{g} \mathrm{L}^{-1}$, sweep from +1.1 to $-0.7 \mathrm{~V}$. Inlay: calibration curve of concentration vs. peak potential.

concentration. None of them produced an electrochemical signal differing from the blank, which indicates very good selectivity of the developed sensor.

Recovery studies were performed over water samples obtained in the Tietê river nearby the Araraquara region. These samples were filtered to remove any solid residues. Then the samples were mixed with phosphate buffer $0.20 \mathrm{~mol} \mathrm{~L}^{-1}, \mathrm{pH} 7.0$ in a one to one proportion. This mixture was spiked with TCP concentrations from 12 to $22 \mathrm{mg} \mathrm{L}^{-1}$; average recoveries obtained were of $102 \%$.

In order to obtain the number of electrons in the electrochemical reaction, the variation of peak potential with the square-wave frequency was studied using the following equation [26]:

$$
E=-\frac{2.3 R T}{2 n F} \log (f)
$$

where $E$ is the potential, $R$ is the ideal gas constant, $f$ is the frequency, $T$ is the temperature, $F$ is the Faraday constant and $n$ is the number of electrons. Using this formula, it was calculated that it is a two-electron reaction, thus authors suggest the reaction shown in Figure 4 [18]. 


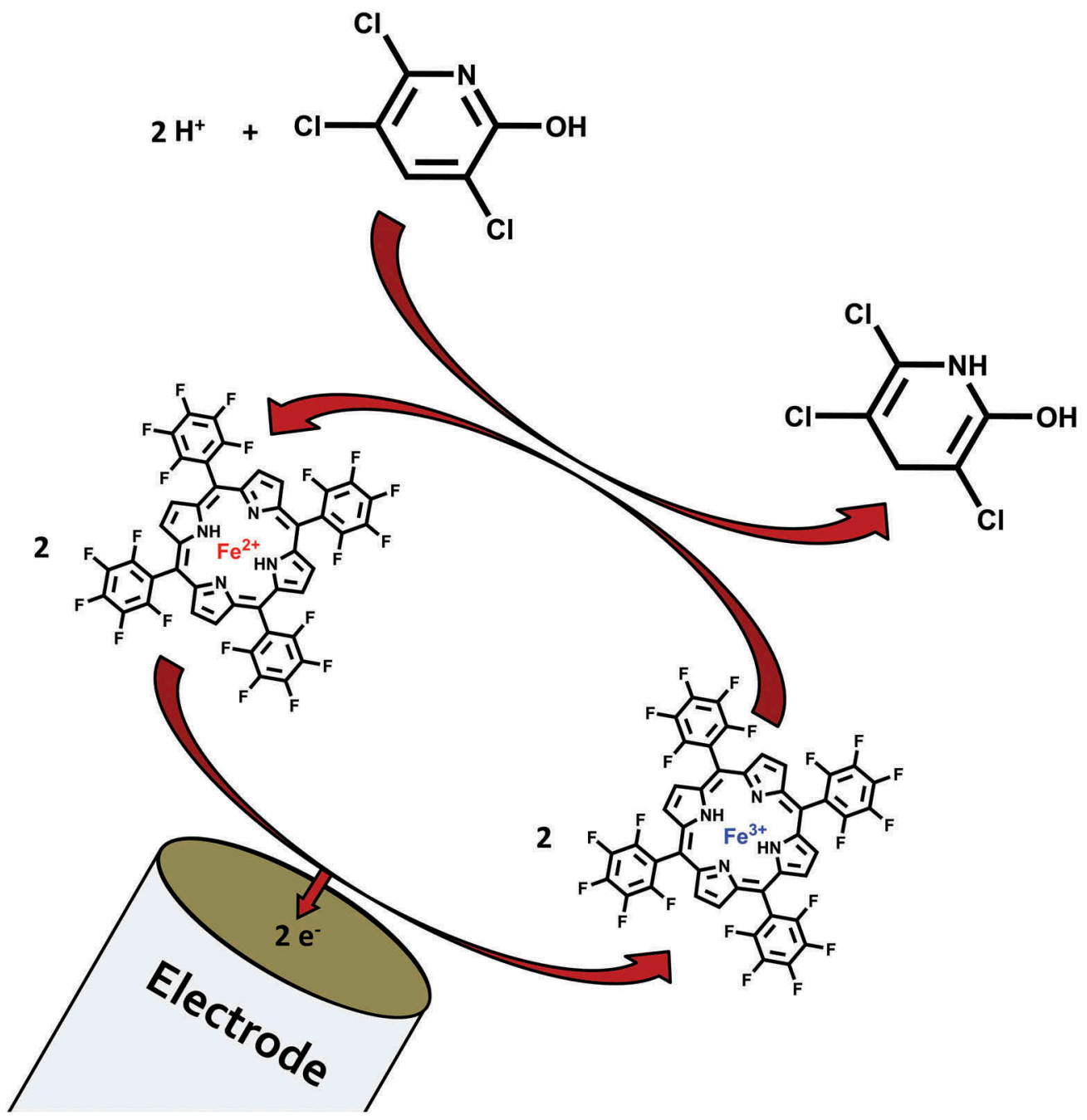

Figure 4. Suggested electrochemical reaction.

\section{Conclusions}

It is herein presented a carbon paste electrode for the determination of TCP, a dangerous widespread pesticide. To obtain a more suitable response the metallic complex FeTPPCI was included within the paste; this complex mimicked the heme $B$ present in the CYP 450. The analytical sensing was performed by square-wave voltammetry, the sensor had adequate selectivity, LOD and LOQ of 2.8 and $9.3 \mathrm{mg} \mathrm{L}^{-1}$, respectively, recoveries around 102\%, 1-month stability and good repeatability.

\section{Acknowledgements}

The authors would like to express their sincerest gratitude and indebtedness to the Research Funding Agencies CNPq - Conselho Nacional de Desenvolvimento Científico e Tecnológico 
(400459/2012-4 and 153409/2010-0) and FAPESP (2016/06926-0). LMG (SFRH/BPD/76544/2011) wishes to acknowledge FCT for his post-doctoral grant.

\section{Disclosure statement}

No potential conflict of interest was reported by the authors.

\section{Funding}

This work was supported by the Conselho Nacional de Desenvolvimento Científico e Tecnológico [153409/2010-0 and 400459/2012-4]; Fundação de Amparo à Pesquisa do Estado de São Paulo [2016/06926-0]; and Fundação para a Ciência e a Tecnologia [SFRH/BPD/76544/2011].

\section{ORCID}

Luís Moreira Gonçalves (D) http://orcid.org/0000-0002-4290-656X

\section{References}

[1] D.L. Eaton, R.B. Daroff, H. Autrup, J. Bridges, P. Buffler, L.G. Costa, J. Coyle, G. McKhann, W.C. Mobley, L. Nadel, D. Neubert, R. Schulte-Hermann and P.S. Spencer, Crit. Rev. Toxicol 38, 1 (2008). doi:10.1080/10408440802272158.

[2] E.M. John and J.M. Shaike, Environ. Chem. Lett 13, 269 (2015). doi:10.1007/s10311-015-0513-7.

[3] J. Fischer, A. Hájková, M. Pereira, M. Křeček, V. Vyskočil and J. Barek, Electrochim. Acta 216, 510 (2016). doi:10.1016/j.electacta.2016.09.013.

[4] D. Catalina Rodríguez, S. Carvajal and G. Peñuela, Talanta 111, 1 (2013). doi:10.1016/j. talanta.2013.03.036.

[5] P.R. Bueno, L.M. Gonçalves, F.C.D. Santos, M.L.D. Santos, A.A. Barros and R.C. Faria, Anal. Lett 46, 258 (2013). doi:10.1080/00032719.2012.713065.

[6] J. Xiong, G. Zhou, Z. Guan, X. Tang, Q. He and L. Wu, J. Liq. Chromatogr. Relat. Technol 37, 1499 (2014). doi:10.1080/10826076.2012.745146.

[7] L.D. Marestoni, A. Wong, G.T. Feliciano, M.R.R. Marchi, C.R.T. Tarley and M.D.P.T. Sotomayor, J. Braz. Chem. Soc 27, 109 (2015). doi:10.5935/0103-5053.20150256

[8] A.B. MacKenzie, F.C.A. Striley, E.R. Biagini, E.L. Stettler and J.C. Hines, Bull. Environ. Contam. Toxicol 65, 1 (2000). doi:10.1007/s0012800086.

[9] F. Delgado Reyes, J.M. Fernández Romero and M.D.L.D. Castro, Fresenius. J. Anal. Chem 372, 366 (2002). doi:10.1007/s00216-001-1184-8

[10] M.A. González-Martínez, R. Puchades, A. Maquieira, J.J. Manclús and A. Montoya, Anal. Chim. Acta 392, 113 (1999). doi:10.1016/S0003-2670(99)00232-9.

[11] E. Watanabe, R. Hoshino, Y. Kanzaki, H. Tokumoto, H. Kubo and H. Nakazawa, J. Agric. Food Chem 50, 3637 (2002). doi:10.1021/jf0114684.

[12] W. Zhang, Y. Tang, D. Du, J. Smith, C. Timchalk, D. Liu and Y. Lin, Talanta 114, 261 (2013). doi:10.1016/j.talanta.2013.06.012.

[13] W.M.J. Chang, Y.C. Lin, W.L. Lo and S.R. Lin, Bull. Environ. Contam. Toxicol 56, 367 (1996). doi:10.1007/s001289900053.

[14] J. Xiong, X. Tang, G. Zhou, Z. Guan and L. Wu, Anal. Methods 5, 536 (2013). doi:10.1039/ C2AY25972A.

[15] G. Peng, Y. Lu, Q. He, D. Mmereki, G. Zhou, J. Chen and X. Tang, J. Sep. Sci 38, 4204 (2015). doi:10.1002/jssc.201500736.

[16] G. Liu, S.L. Riechers, C. Timchalk and Y. Lin, Electrochem. Commun 7, 1463 (2005). doi:10.1016/j.elecom.2005.10.005. 
[17] L. Wang, D. Lu, J. Wang, D. Du, Z. Zou, H. Wang, J.N. Smith, C. Timchalk, F. Liu and Y. Lin, Biosens. Bioelectron 26, 2835 (2011). doi:10.1016/j.bios.2010.11.008.

[18] T.M. Do Prado, M.V. Foguel, L.M. Gonçalves and M.D.P.T. Sotomayor, Sensors Actuators B Chem 210, 254 (2015). doi:10.1016/j.snb.2014.12.108.

[19] C. Batchelor-McAuley, L.M. Goncalves, L. Xiong, A.A. Barros and R.G. Compton, Chem. Commun 46, 9037 (2010). doi:10.1039/c0cc03961f.

[20] L.M. Gonçalves, C. Batchelor-McAuley, A.A. Barros and R.G. Compton, J. Phys. Chem. C 114, 14213 (2010). doi:10.1021/jp1046672.

[21] E.M. Tavares, A.M. Carvalho, L.M. Gonçalves, I.M. Valente, M.M. Moreira, L.F. Guido, J.A. Rodrigues, T. Doneux and A.A. Barros, Electrochim. Acta 90, 440 (2013). doi:10.1016/j. electacta.2012.12.040.

[22] E.C. Figueira, L.C.S. Neres, M.R.S. Ruy, G.F. Troiano and M.D.P.T. Sotomayor, Anal. Methods 8, 6353 (2016). doi:10.1039/C6AY01830K.

[23] A.M. Carvalho, L.M. Gonçalves, I.M. Valente, J.A. Rodrigues and A.A. Barros, Phytochem. Anal 23, 396 (2012). doi:10.1002/pca.1370.

[24] V. Mirceski, R. Gulaboski, M. Lovric, I. Bogeski, R. Kappl and M. Hoth, Electroanalysis 25, 2411 (2013). doi:10.1002/elan.201300369.

[25] M.D.P.T. Sotomayor, A. Sigoli, M.R.V. Lanza, A.A. Tanaka and L.T. Kubota, J. Braz. Chem. Soc 19, 734 (2008). doi:10.1590/S0103-50532008000400018.

[26] D. De Souza, S.A.S. Machado and L.A. Avaca, Quím Nova 26, 81 (2003). doi:10.1590/S010040422003000100015 